\title{
Deformation Monitoring in an Alpine Mining Area in the Tianshan Mountains Based on SBAS-InSAR Technology
}

\author{
Qingsong Du $\mathbb{D}^{1,2,3}$ Guoyu Li $\mathbb{D}^{1,2}$ Yu Zhou $\mathbb{D}^{1,2,3}$ Mingtang Chai ${ }^{1,},{ }^{4}$ Dun Chen $\mathbb{D}^{1,2}$ \\ Shunshun Qi ${ }^{1},{ }^{1,2,3}$ and Gang $W u$ iD ${ }^{1,2,3}$ \\ ${ }^{1}$ State Key Laboratory of Frozen Soil Engineering, Northwest Institute of Eco-Environment and Resources, \\ Chinese Academy of Sciences, Lanzhou 730000, China \\ ${ }^{2}$ Da Xing'anling Observation and Research Station of Frozen-Ground Engineering and Environment, \\ Northwest Institute of Eco-Environment and Resources, Chinese Academy of Sciences, Jiagedaqi 165000, China \\ ${ }^{3}$ College of Resources and Environment, University of Chinese Academy of Sciences, Beijing 100049, China \\ ${ }^{4}$ School of Civil and Hydraulic Engineering, Ningxia University, Yinchuan 750021, China \\ Correspondence should be addressed to Guoyu Li; guoyuli@lzb.ac.cn
}

Received 22 March 2021; Revised 8 April 2021; Accepted 8 April 2021; Published 19 April 2021

Academic Editor: Xiao Dong Zhao

Copyright ( 2021 Qingsong Du et al. This is an open access article distributed under the Creative Commons Attribution License, which permits unrestricted use, distribution, and reproduction in any medium, provided the original work is properly cited.

The fragile habitat of alpine mining areas can be greatly affected by surface disturbances caused by mining activities, particularly open-pit mining activities, which greatly affect the periglacial environment. SBAS-InSAR technology enables the processing of SAR images to obtain highly accurate surface deformation information. This paper applied SBAS-InSAR technology to obtain three years of surface subsidence information based on the 89-scene Sentinel-1A SLC products, covering a mining area (tailings and active areas) in the Tianshan Mountains and its surroundings from $25^{\text {th }}$ December 2017 to $2^{\text {nd }}$ January 2021 . The data were adopted to analyze the characteristics of deformation in the study region and the mining areas, and the subsidence accumulation was compared with field GNSS observation results to verify its accuracy. The results showed that the study area settled significantly, with a maximum settlement rate of $-44.80 \mathrm{~mm} / \mathrm{a}$ and a maximum uplift rate of $28.04 \mathrm{~mm} / \mathrm{a}$. The maximum settlement and accumulation of the whole study area over the three-year period were $-129.39 \mathrm{~mm}$ and $60.49 \mathrm{~mm}$, respectively. The mining area had a settlement value of over $80 \mathrm{~mm}$ over the three years. Significantly, the settlement rates of the tailings and active areas were $-35 \mathrm{~mm} / \mathrm{a}$ and $-40 \mathrm{~mm} / \mathrm{a}$, respectively. Debris accumulation in the eastern portion of the tailings and active areas near the mountain was serious, with accumulation rates of $25 \mathrm{~mm} / \mathrm{a}$ and $20 \mathrm{~mm} / \mathrm{a}$, respectively, and both had accumulation amounts of around $70 \mathrm{~mm}$. For mine tailing pile areas with river flows, the pile locations and environmental restoration should be appropriately adjusted at a later stage. For gravel pile areas, regular cleaning should be carried out, especially around the mining site and at the tunnel entrances and exits, and long-term deformation monitoring of these areas should be carried out to ensure safe operation of the mining site. The SBAS-InSAR measurements were able to yield deformations with high accuracies over a wide area and cost less human and financial resources than the GNSS measurement method. Furthermore, the measurement results were more macroscopic, with great application value for surface subsidence monitoring in alpine areas.

\section{Introduction}

Mining activity can cause surface deformations and negatively impacts the environment $[1,2]$. If rehabilitation measures are not handled properly, they can lead to serious subsequent disasters such as mine collapse [3], slope instability [4], vegetation death over large areas $[2,5]$, and severe water-soil erosion [3]. These potential threats and problems are more prominent in high-altitude areas due to the fragile habitats therein [2]. The key to solving these problems is to provide theoretical support for decisionmaking based on a large amount of basic data such as surface deformation data. Ground settlement [6] data provide an understanding of changes in mining areas and the surrounding environment, contributing to their sustainable development. Subsidence data can also provide synchronous 
information on how to develop in areas containing perilous rocks, providing a basic foundation for mining safety in cold-plateau regions.

In recent years, with the development of computer technology, remote sensing (RS), and geographic information system (GIS) technology [7-9], increasingly more novel geographic analysis methods [10-12] have been used for the dynamic monitoring of surface subsidence in mining areas, among which monitoring based on interferometric synthetic aperture radar (InSAR) technology [13-15] has performed excellently. One of the advantages of InSAR over traditional time-consuming and costly monitoring methods, such as level measurements and global positioning satellite (GPS) measurements, is that it has all-day, all-weather $[13,16]$ observation capability. Moreover, microwaves can effectively penetrate the atmosphere and are less affected by water vapor and surface vegetation [17]. In addition, as more and more synthetic aperture radar (SAR) satellites have been launched, increasingly more materials are accessible $[16,18-21]$, and the data acquisition cycles have become shorter. As a result, the accuracy of these measurements has greatly improved. InSAR has the added advantage of obtaining ground deformation information over large areas at a relatively small cost. As a corollary, deformation measurements based on InSAR have becoming increasingly popular [21].

So far, InSAR technology has evolved from traditional differential interferometric synthetic aperture radar (DInSAR) [22, 23] to multitemporal InSAR (MT-InSAR) [24] technologies, including persistent scatterer InSAR (PSInSAR) [25-27], small baseline subsets InSAR (SBASInSAR) [28], and distributed scatterer InSAR (DS-InSAR) [29]. In addition, to compensate for the deficiency that D-InSAR or MT-InSAR can only acquire line-of-sight (LOS) direction deformation, the multiaperture InSAR (MAI) [30] technique has been proposed to acquire deformation information in the azimuthal direction (i.e., satellite flight direction).

These InSAR techniques have been used in a wide range of deformation monitoring applications, such as urban ground settlement [31-33], mine subsidence [34-41], earthquakes and plate movements [42-45], volcanic eruptions [46-48], infrastructure deformation [49-51], glacial drift [52-55], permafrost deformation [56-60], and landslides [61-63]. Compared to other MT-InSAR techniques, SBAS-InSAR has the advantage of being able to overcome atmospheric interference and requires a relatively small amount of data $[14,16,21]$. This method has been widely used for surface deformation monitoring with excellent results [28, 31-63].

For the above reasons, to understand the dynamic changes of subsidence in alpine mining areas, this study focuses on a mining area in the Tianshan Mountains of China as the research object, which consists of 89 scenes of Sentinel-1A level-1 single look complex (SLC) data processed via SBAS-InSAR technology to obtain the surface subsidence [35] information of the area. The subsidence information is analyzed to understand surface subsidence around the mining site and to provide recommendations for mining activities. The cumulative deformation information is also compared with data obtained from in situ global navigation satellite system (GNSS) measurements to verify the accuracy of SBAS-InSAR technology for surface deformation monitoring and subsidence measurements in alpine mining areas. From this, the extent of impact of mining activity on local environment can be understood. In addition, the obtained deformation over a large area can be used as fundamental information to provide a theoretical basic for mining policy, which is of great value to ensure environmental sustainability.

\section{Regional Characteristics}

The study area (Figure 1) is located in the eastern Tianshan Mountains, with geographical coordinates of $84.95-85.12^{\circ} \mathrm{E}$ and $43.28-43.35^{\circ} \mathrm{N}$ (as shown by the red box in Figure 1(a)). Its altitude ranges from $3,160 \mathrm{~m}$ to $4,365 \mathrm{~m}$ above the sea level (m.a.s.l.), with an average altitude of $3,839 \mathrm{~m}$. The annual temperature has a maximum of $16^{\circ} \mathrm{C}$ and a minimum of $-30^{\circ} \mathrm{C}$ [2], and it is a typical high-cold and high-altitude area. The snowline is 3,700-3,900 m.a.s.l., and the areas above the snowline are covered with glaciers, snow cover, permafrost, rock glaciers, and other periglacial geomorphology. The watershed located in the southwest of the mining area divides the rivers into two basins flowing south and north [9]. The south-flowing rivers converge with the Yili River, which is dominated by small rivers. The northflowing rivers empty into Noor Lake, which eventually feeds into the Manas River. The maximum daily precipitation is $146 \mathrm{~mm}$, the annual rainfall exceeds $1,000 \mathrm{~mm}$, the evaporation is $425 \mathrm{~mm}$, the maximum wind speed is $12 \mathrm{~m} / \mathrm{s}$, the average humidity is about $43 \%$, and the wind direction is mainly north-northeast [2]. From October to April, the average temperature is below freezing, and solid precipitation such as hail and snowfall dominates this period. In contrast, from July to September, there is relatively little snowfall and warmer temperatures, making this the season appropriate for grass growth.

The mine is located along the watershed of the study area, which consists of a large open-pit iron ore mine where the extracted ore is sorted by a mobile crushing and dry sorting station [64]. The geology consists of an erosiondenudation-tectonic alpine landform and a denudationdeposition alpine-valley landform with extensive granite distribution. Two major sections, a tailings stockpile (irregular blue frame in Figure 1(c)) and an active area (irregular black frame in Figure 1(c)), are the focus of this study. The tailings stockpile includes a beneficiation region, and the active area consists of an open-pit mining area (irregular red frame in Figure 1(c)), early prospecting area, and part of the tailings waste stockpile. The rocks around the mining site are heavily weathered [64] and often have fallen rock accumulations. In addition, the rocks are subject to strong cryogenesis, gelifraction, and tectogenesis, inducing a high risk of potential geological hazards. This, coupled with the impact of the mining activities, increases the susceptibility to geological hazards, while frequent weather changes, such as high winds, snow, and hail, can easily cause 


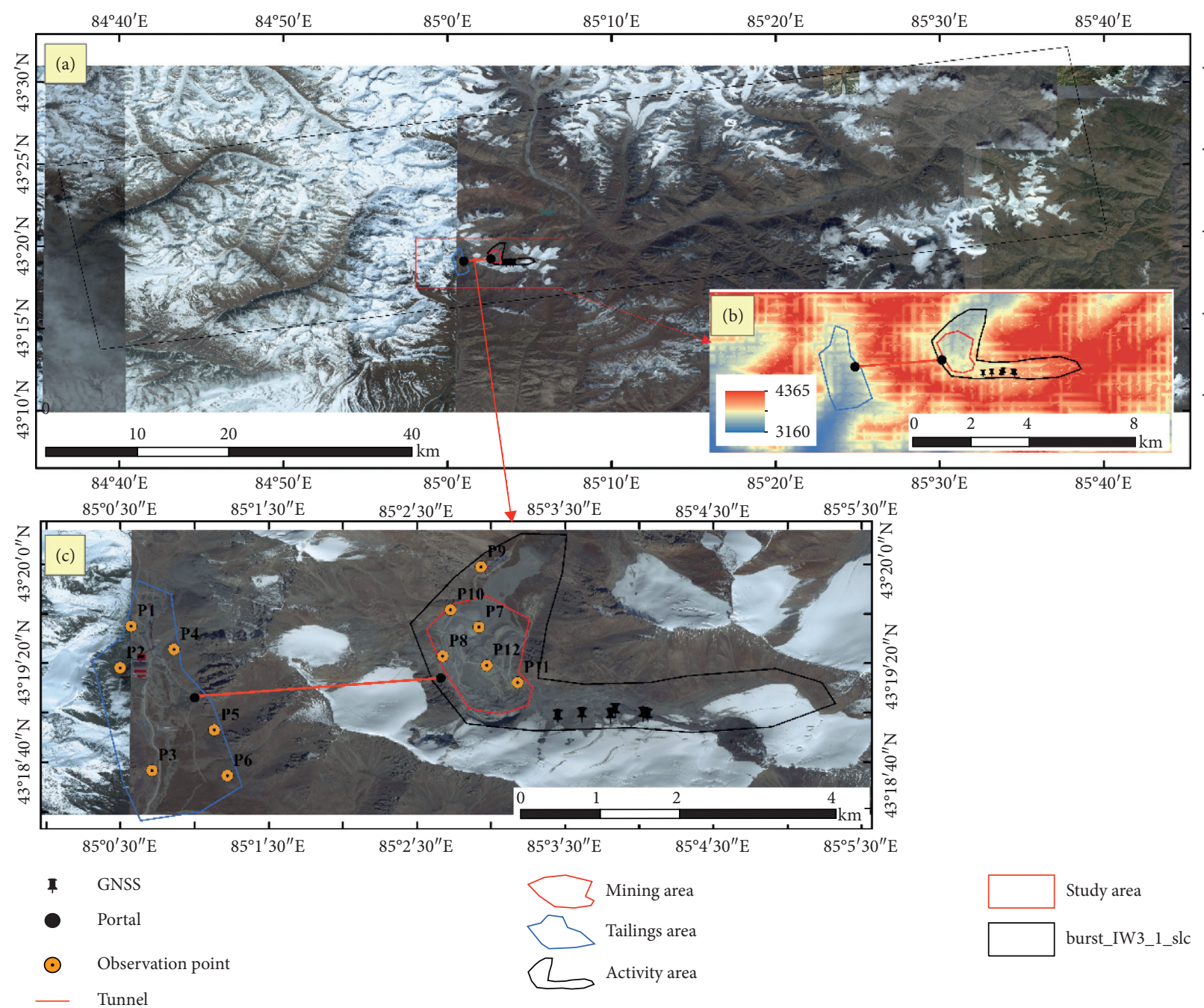

FIGURE 1: Geographical location of the study area: (a) position of the entire study area in the Sentinel-1A image; (b) DEM of the study area; (c) an enlarged view of the location of the mining area, observation points, and the GNSS points.

meteorological disasters and lead to a range of environmental and geological hazard problems.

\section{Data and Methods}

Sentinel-1A level-1 SLC products are available for free download from the ASF website (https://vertex.daac.asf. alaska.edu/). The time span is from $25^{\text {th }}$ December 2017 to $2^{\text {nd }}$ January 2020, with an average of more than two images per month, excluding cases where no data are available, for a total of 89 scene images. The precise orbital data corresponding to each scene image is available from the ESA website (https://qc.sentinel1.eo.esa.int/). There are two types of orbital data: one is the precise data created 21 days after the GNSS downlink date, and the other is the restituted product generated within $3 \mathrm{~h}$ of receiving the GNSS data. The precision orbital data with ephemerides have positions with accuracies better than $5 \mathrm{~cm}$, and the other data have accuracies of $10 \mathrm{~cm}$. The orbital data used here are the products with precise ephemerides. The digital elevation model (DEM) of the study area is the USGS EROS Archive-
Digital Elevation-Shuttle Radar Topography Mission (SRTM) 1 Arc-Second Global, which has a spatial resolution of $30 \mathrm{~m}$ and can be obtained from the USGS EarthExplorer website (https://earthexplorer.usgs.gov/).

The GNSS static monitoring network system is located at the southwestern foot of the mountain near the mining area (Figure 1(c)), which can be used to monitor threedimensional (3D) ground surface deformation information, and it consists of nine parts (Figure 2). The monitoring system which consists of six stations in total, one base station and five observation stations, started working on $9^{\text {th }}$ October 2019. After the complex calculation between these two kinds of data, the deformation, with a temporal resolution of seconds, can be obtained. However, due to the high temperature variability in the area and the low winter temperatures, part of the stations has experienced some anomalies, and the deformation data monitored at certain times are missing. The GNSS measured deformation data used for the comparison span from $16^{\text {th }}$ October 2019 to $31^{\text {st }}$ May 2020 and condition with no data or abnormal data in this period have been rejected. 


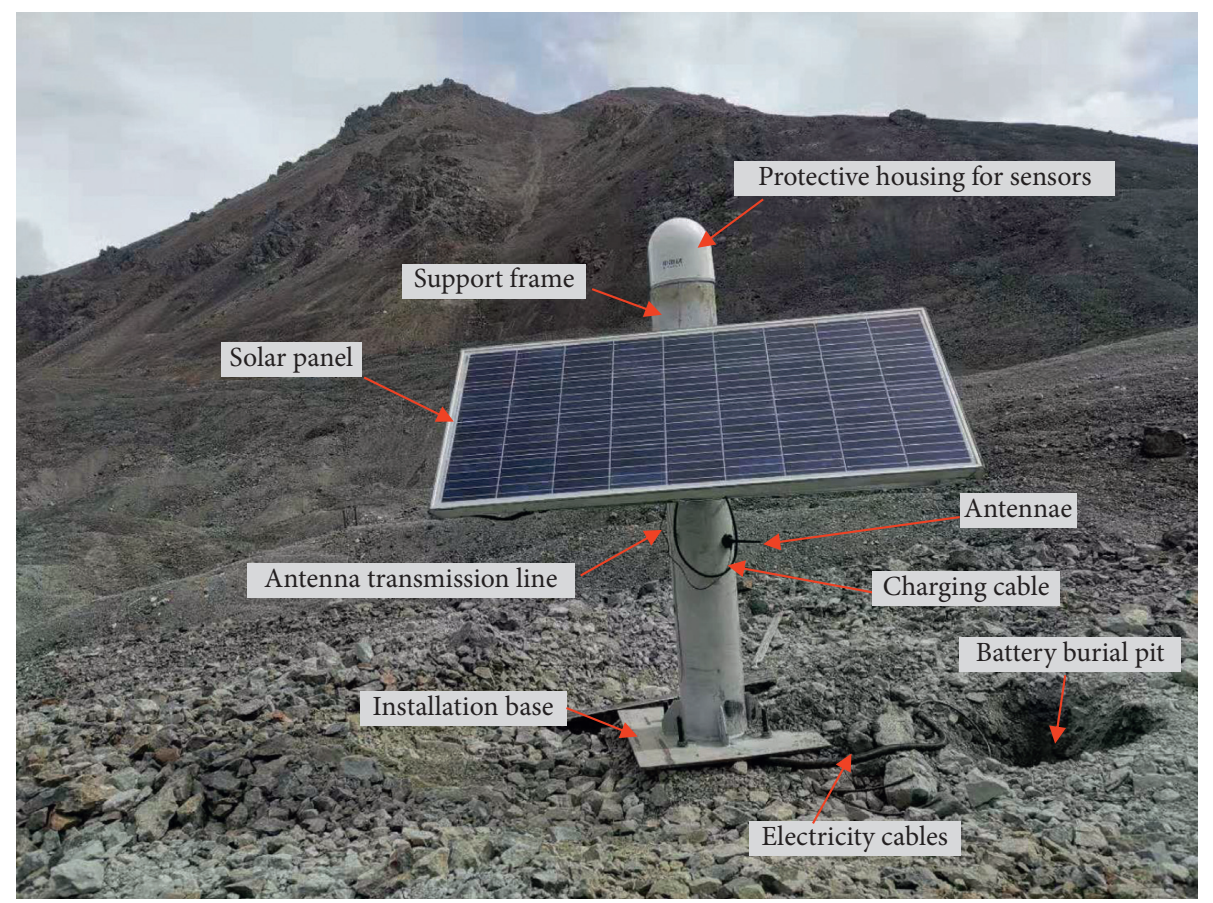

FIGURE 2: GNSS ground deformation monitoring instrument.

To better analyze the settlement characteristics around the mining site, six observation points were selected around each of the tailings stockpile area and the active area containing the mining activities, with six more based on topography, ground cover, and runoff distribution, for a total of 12 points, as shown in Figure 1(c). More information can be seen in Table 1.

The software used in this paper includes ArcGIS 10.6, ENVI5.3, SARscape5.2.1, OriginLab2017, and Global Mapper 14. The workflow mainly consists of data preprocessing, SBAS-InSAR processing, and data analysis, as shown in Figure 3.

3.1. Data Preprocessing. This process aims to convert the format of the data so that the different software platforms can recognize them and clip the data, thus reducing the time spent on data processing and improving the overall efficiency. Firstly, the region of interest (ROI) is mapped and converted to .shp format. Then, the DEM in .tiff format is converted to binary format using SARscape [7], and Global Mapper is applied to create isoheights of the total study area with a spacing distance of $200 \mathrm{~m}$. After these two steps, the SLC data are imported and set at a resolution of $20 \mathrm{~m} \times 20 \mathrm{~m}$. Then, the processing images data (raster) area is sectioned with the ROI vector data (.shp). The resolution of the image depends on the pixel spacing slant range, pixel spacing azimuth, incidence angle, and multilook number, which is calculated as

$$
\begin{aligned}
& R_{s r}=\frac{P_{s r}}{\sin (\theta)} \times N_{s r}, \\
& R_{a}=P_{a} \times N_{a},
\end{aligned}
$$

where $R_{s r}$ is the range slant resolution, $R_{a}$ is the azimuth resolution, and $P_{s r}$ and $P_{a}$ are the pixel spacings of the slant range and azimuth, respectively, all in units of $\mathrm{m} . N_{s r}$ is the number of slant range looks and $N_{a}$ is the number of azimuth looks; both are positive integers. $\theta$ is the angle of incidence in degrees.

The images used here were obtained from an ascending attitude at an angle of incidence of $39.08^{\circ}$, with pixel spacings of $3.73 \mathrm{~m}$ and $13.89 \mathrm{~m}$ for the slant range and azimuth, respectively. To ensure that we yielded a target deformation map with a spatial resolution of $20 \mathrm{~m} \times 20 \mathrm{~m}$, the multilook numbers of the slant range and the azimuth, which can be calculated by (1) and (2), were set as five and one, respectively.

Based on the SARscape software for baseline estimation and SBAS data processing, a temporal baseline threshold of $180 \mathrm{~d}$ and a spatial baseline threshold of $2 \%$ of the critical baseline were set for all data processing to ensure the accuracy of the results and to avoid spatiotemporal decoherence of the data as much as possible.

3.2. SBAS-InSAR Processing. A differential interferogram and coherence intensity graph are obtained by differential interference processing. The final output of this step is a flattened interferogram, where if the constant phase caused by the acquisition geometry and an input DEM are provided, the topographic phase is removed. A Goldstein adaptive filter [65] is chosen to reduce interference from noise phases while outputting the filtered product. Interferometric coherence, which is an indicator of the phase quality and the master intensity filtered image, is also generated. Then, the minimum cost flow method [66] with a coherence threshold 
TABLE 1: Basic information of the deformation observation points.

\begin{tabular}{|c|c|c|c|c|c|}
\hline Region & Name & Latitude N $\left({ }^{\circ}\right)$ & Longitude E $\left({ }^{\circ}\right)$ & Altitude (m) & Surface features \\
\hline \multirow{6}{*}{ Tailings area } & P1 & 43.3264 & 85.0095 & 3571.37 & Tailings stockpile, close to river \\
\hline & $\mathrm{P} 2$ & 43.3217 & 85.0083 & 3662.99 & Close to the living area \\
\hline & P3 & 43.3102 & 85.0119 & 3639.23 & Downstream of the river \\
\hline & $\mathrm{P} 4$ & 43.3238 & 85.0143 & 3562.51 & Gravel slopes \\
\hline & P5 & 43.3147 & 85.0189 & 3644.24 & Gravel, close to road, portal \\
\hline & P6 & 43.3096 & 85.0203 & 3668.44 & Gravel slopes \\
\hline \multirow{6}{*}{ Activity area } & P7 & 43.3263 & 85.0486 & 3629.46 & Close to road, gravel slag \\
\hline & P8 & 43.3230 & 85.0446 & 3592.24 & Close to portal, gravel slag \\
\hline & P9 & 43.3331 & 85.0489 & 3685.94 & Tailings stockpile, close to river \\
\hline & $\mathrm{P} 10$ & 43.3282 & 85.0454 & 3614.84 & Foot of the mountain, near road \\
\hline & P11 & 43.3201 & 85.0530 & 3483.14 & The edge of the mine \\
\hline & $\mathrm{P} 12$ & 43.3220 & 85.0495 & 3611.80 & Foot of the mountain, near mining \\
\hline
\end{tabular}

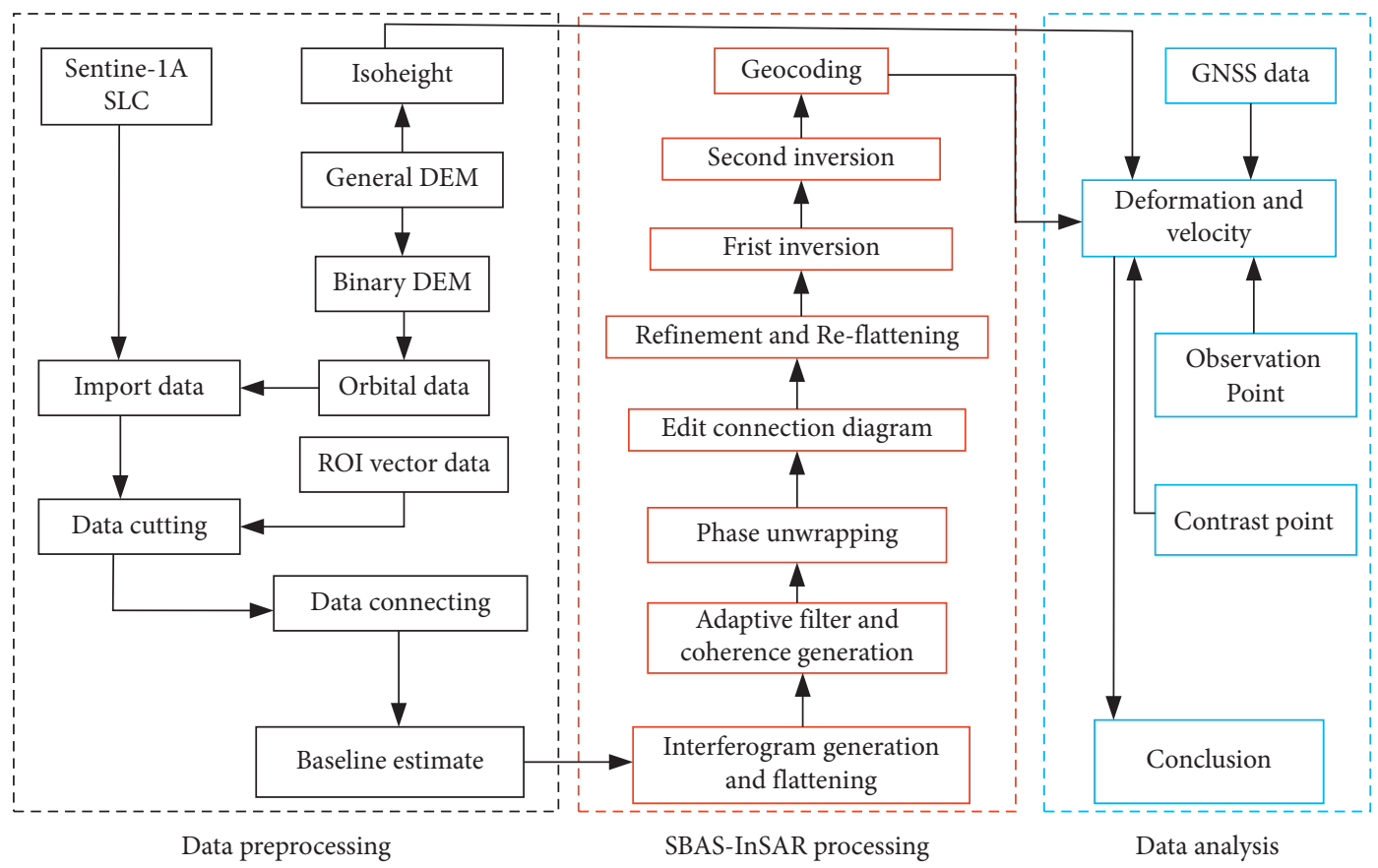

FIGURE 3: Data processing flow chart.

of 0.35 to unwrap the phase, which is obtained after the above processing, is employed. Finally, the interferometric image pairs are edited according to the unwrapping result, the coherence intensity graph, and the flattened interferogram to ensure that the connection diagram is correct, and image pairs are removed if the value of the coherence intensity graph is low.

After the editing process, ground control points (GCP) are selected for refinement and reflattening processing to accurately estimate the orbital parameters so that the unwrapped results are refined and the residual phase is removed. The deformation rate and residual topography are estimated by the first inversion, and the atmospheric phase error is removed by the second inversion. Multiple time series displacements are calculated and the SBAS-InSAR results are geocoded. The results consist of LOS cumulative displacements, in units of $\mathrm{mm}$, and multitime series rate deformation, in units of $\mathrm{mm} / \mathrm{a}$.
3.3. Data Analysis. To visualize the displacement results and extract the features of the deformation information, we divided the results into three-year parts with a time interval of about three months in every year. We note that this choice is in keeping with the changing seasons. Then, the subsidence rate map was used to analyze the subsidence features around the mining site, select and visualize typical sites, extract their multitime subsidence information to understand the subsidence characteristics, and map the data. Finally, the subsidence information for the comparison points (CPs) was extracted and compared with the GNSS data, which were obtained from observations made during the same measurement period to verify the accuracy of the SBAS-InSAR measurements in the study area. These two kinds of data were obtained during the same observing period and from the same observing places so that the accumulated sedimentation obtained from the two methods 
could be compared. The accumulated sedimentation can be calculated as follows:

$$
\Delta D=D_{2}-D_{1},
$$

where $\Delta D$ is the accumulated sedimentation and $D_{1}$ and $D_{2}$ are the sedimentations of the observational starting data and end data, respectively, all units in $\mathrm{mm}$.

\section{Results}

4.1. Baseline Estimation. The baseline information (Figures 4 and 5) of the Sentinel-1A data was obtained after calculation. The image from $21^{\text {st }}$ October 2018 (yellow dots in Figures 4 and 5) was finally identified as the super master image, and the remaining images were paired with this master image for interferometric processing, which resulted in 1029 pairs of interferometric images (Figure 5). The maximum absolute normal baseline was $116.56 \mathrm{~m}$, the minimum absolute baseline was $0.71 \mathrm{~m}$, and the average was $50.51 \mathrm{~m}$. The time baseline ranged from $12 \mathrm{~d}$ to $180 \mathrm{~d}$. The results of processing indicated that the data were sufficient for use in the SBASInSAR process and they contained little decoherence.

4.2. Deformation Velocity. The deformation rate of the entire study area is shown in Figure 6. Data throughout the study area ranged from $-44.80 \mathrm{~mm} / \mathrm{a}$ to $28.04 \mathrm{~mm} / \mathrm{a}$, with significant subsidence at the mining area location, with rates in excess of $-40 \mathrm{~mm} / \mathrm{a}$. Significant subsidence funnels exist in the northwest and southeast corners of the active area. Combined with the field investigations carried out in September 2018, a large accumulation of tailings waste was found in the northwest corner, distributing a river that flows from the mine site to Noel Lake. At the southeast foot, ground ice is developed, and a large number of turn-hole steel pipes left over from earlier prospecting are distributed, with the tops of the pipes ranging from 1 to $2 \mathrm{~m}$ from the present ground surface. The subsidence may be caused by the scouring and transporting actions of the river in the northwest. Besides, sinking in the southeast section of the mining area may be due to melting of this ground ice caused by early prospecting activities. In addition, there is a tendency for accumulation along the eastern part of the active area near the mountain, with an accumulation rate of greater than $20 \mathrm{~mm} / \mathrm{a}$, mainly due to rolling accumulation towards the foot of the mountain as the dangerous rock is broken by gelifraction, frost action, and physical weathering, while activities in the mine also likely increase accumulation at the foot of the mountain.

The deformation rate characteristics of the tailings pile area are similar to those of the active and mining areas, with significant subsidence in the waste piles distributed along the river in the west and uplift in the western part near the hills. Settlement is mostly pronounced in the northwest and southwest, with deformation rates exceeding $-35 \mathrm{~mm} / \mathrm{a}$ in the north and averaging $30 \mathrm{~mm} / \mathrm{a}$ in the southwest, while in the east, at the foot of the hillside, the piles are clearly deposited at rates greater than $25 \mathrm{~mm} / \mathrm{a}$.

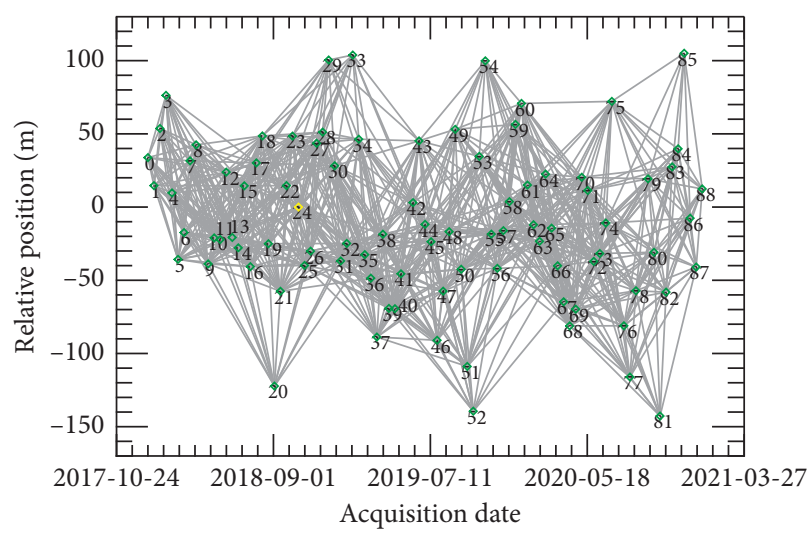

FIgURE 4: Spatiotemporal baseline combination of the data collection.

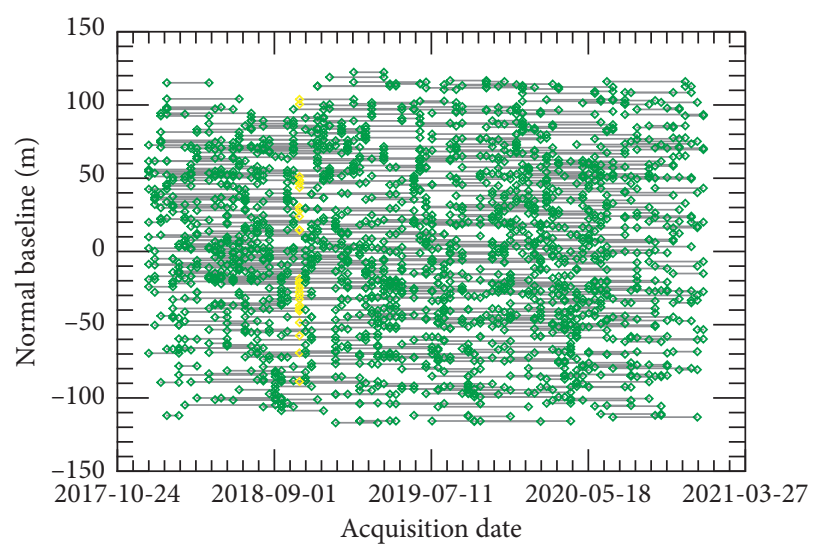

FiguRe 5: Interferometric image pairs of the data.

The relationship between the deformation velocity and altitude (Figure 7) shows that as the altitude rises, the velocity gets larger. Combined with Table 1 and Figures 1 and 6, we can understand that P1-P6 are located in the tailings area, which is used for mineral dressing and tailings stockpiling, while $\mathrm{P} 1-\mathrm{P} 3$ are located to the west of the area, and P4-P6 are near the mountain to the east of the tailings area. The deformation velocity shows that with the exception of P5, which is located in the accumulation zone, all other points are located in the settlement zone, with $\mathrm{P} 1, \mathrm{P} 3$, and $\mathrm{P} 4$ all having settlement rates in excess of $20 \mathrm{~mm} / \mathrm{a}$. P7-P12 are included in the activity area, where $\mathrm{P} 8, \mathrm{P} 9$, and $\mathrm{P} 10$ are located in the northwest of the area, P7 is in the central part near the mining working area, and P11 and P12 are in the southeast; indeed, all points except $\mathrm{P} 9$ are within the mining area. The deformation velocities of P7, P8, and P11 are positive and the other three are negative.

In general, the area over which the tailings were deposited has settled significantly, with an average settlement rate of over $35 \mathrm{~mm} / \mathrm{a}$ and more than $40 \mathrm{~mm} / \mathrm{a}$ in areas that experience river flowing. Mining activity may accelerate the surrounding perilous rock with frost fissure and frost splitting. Due to the gelifraction of glaciers and ice and the engineering blasting of the mining activity, there is large accumulation of sediment at 


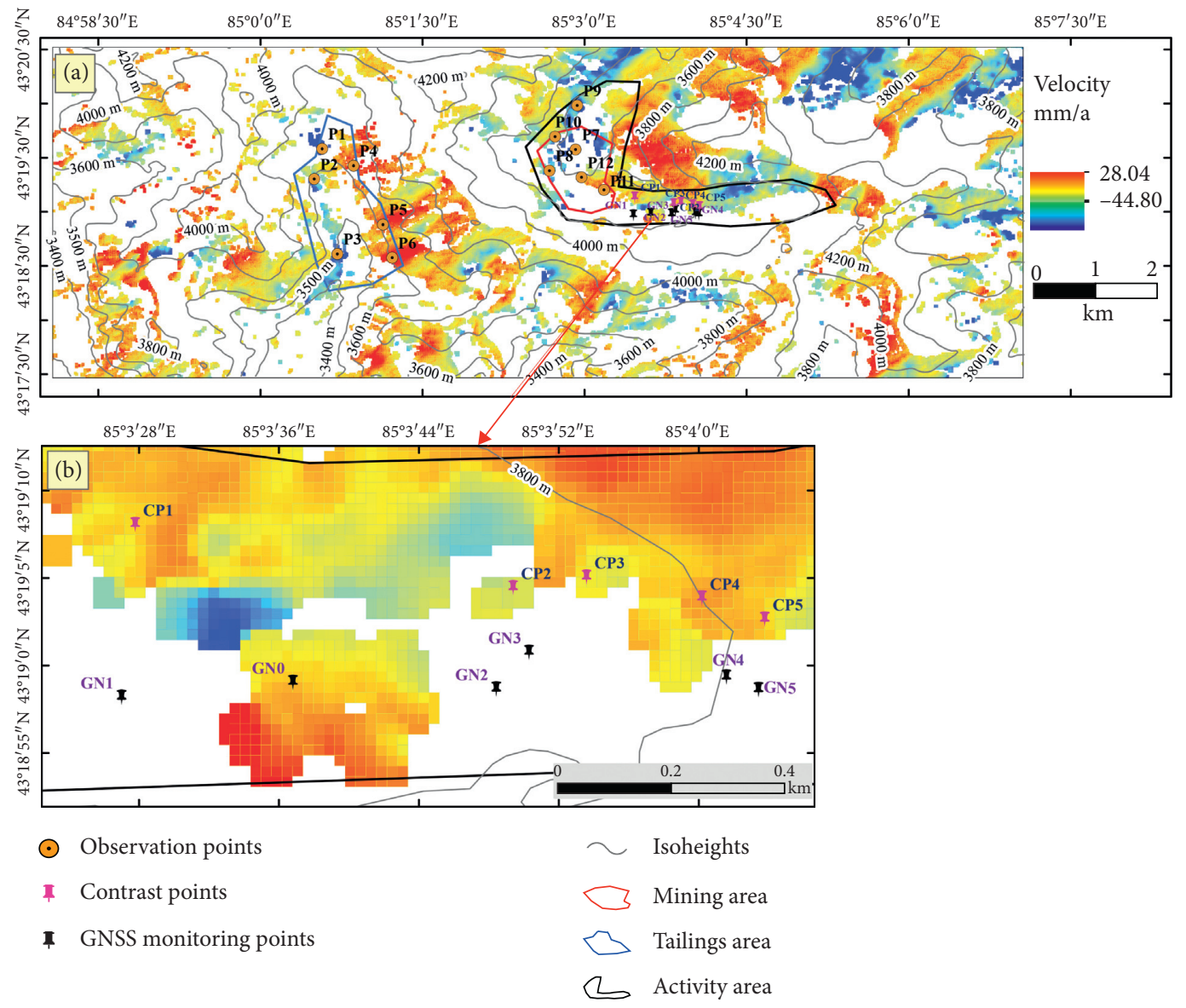

FIGURE 6: Deformation velocity in the study area.

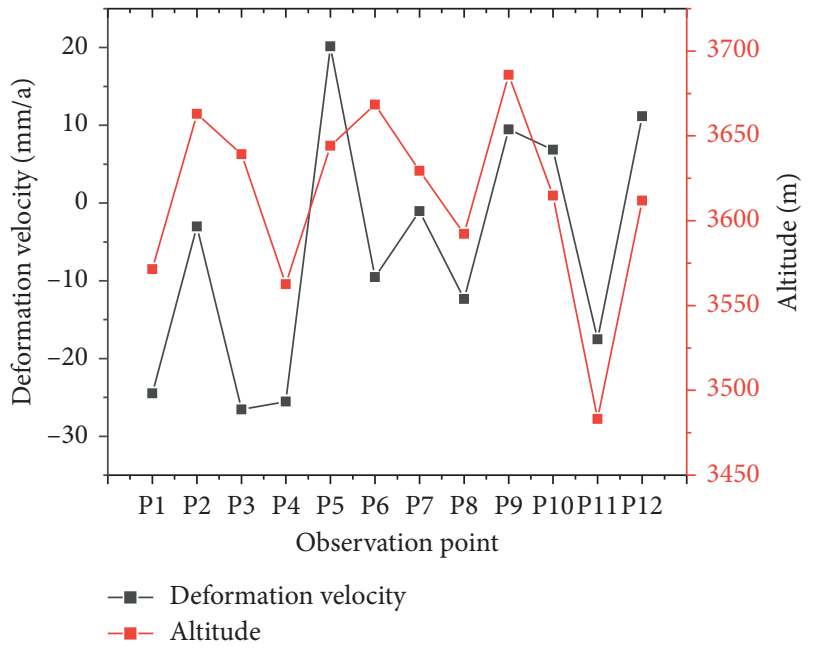

FIgURE 7: Relationship between the deformation velocity and altitude of the observation points.

the foot of the slope around the mining site. The settlement rate here is over $20 \mathrm{~mm} / \mathrm{a}$, which is a cause of concern. The prolonged and rapid accumulation of debris is a potential risk that could threaten the safety of mining personnel, and as the tailings area and mining area are connected by tunnels (Figure 1(c)), the safety of traffic should be a further concern.
4.3. Deformation Characteristics. Taking the LOS deformation on $25^{\text {th }}$ December 2017 as a starting point, the deformation of each subsequent scene image was calculated according to (3). The 89-scene deformation results were divided into three groups at three-month intervals, with each group including a whole freeze-thaw cycle in a year, which allowed for better consistency with seasonal changes. The results are shown in Figures 8-10, corresponding to 2018, 2019, and 2020, respectively. Cold colors indicate surface deformation away from the satellite while warm colors represent displacements towards the sensors along LOS.

Comparison of the cumulative amount of minimum deformation values for these three years shows that the amount of subsidence in the study area gradually increased with date, decreasing from $-12.31 \mathrm{~mm}$ on $31^{\text {st }}$ March 2018 to $-141.70 \mathrm{~mm}$ on $21^{\text {st }}$ December 2020, with a deformation variable of up to $129.39 \mathrm{~mm}$. A decrease of $79.75 \mathrm{~mm}$ occurred from $31^{\text {st }}$ March 2018 to $27^{\text {th }}$ December 2019, and a fall of $82 \mathrm{~mm}$ transpired from $26^{\text {th }}$ March 2019 to $21^{\text {st }}$ December 2020. The cumulative lift during the years 2018, 2019, and 2020 was $33.26 \mathrm{~mm}$, $32.36 \mathrm{~mm}$, and $37.22 \mathrm{~mm}$, respectively. Meanwhile, the maximum accumulation in the study area increased by $60.49 \mathrm{~mm}$ from $25.93 \mathrm{~mm}$ on $31^{\text {st }}$ March 2018 to $21^{\text {st }}$ December 2020. However, unlike the changes in the minimum deposition accumulation, the maximum accumulation values fluctuated and changed rather than increasing over time. 


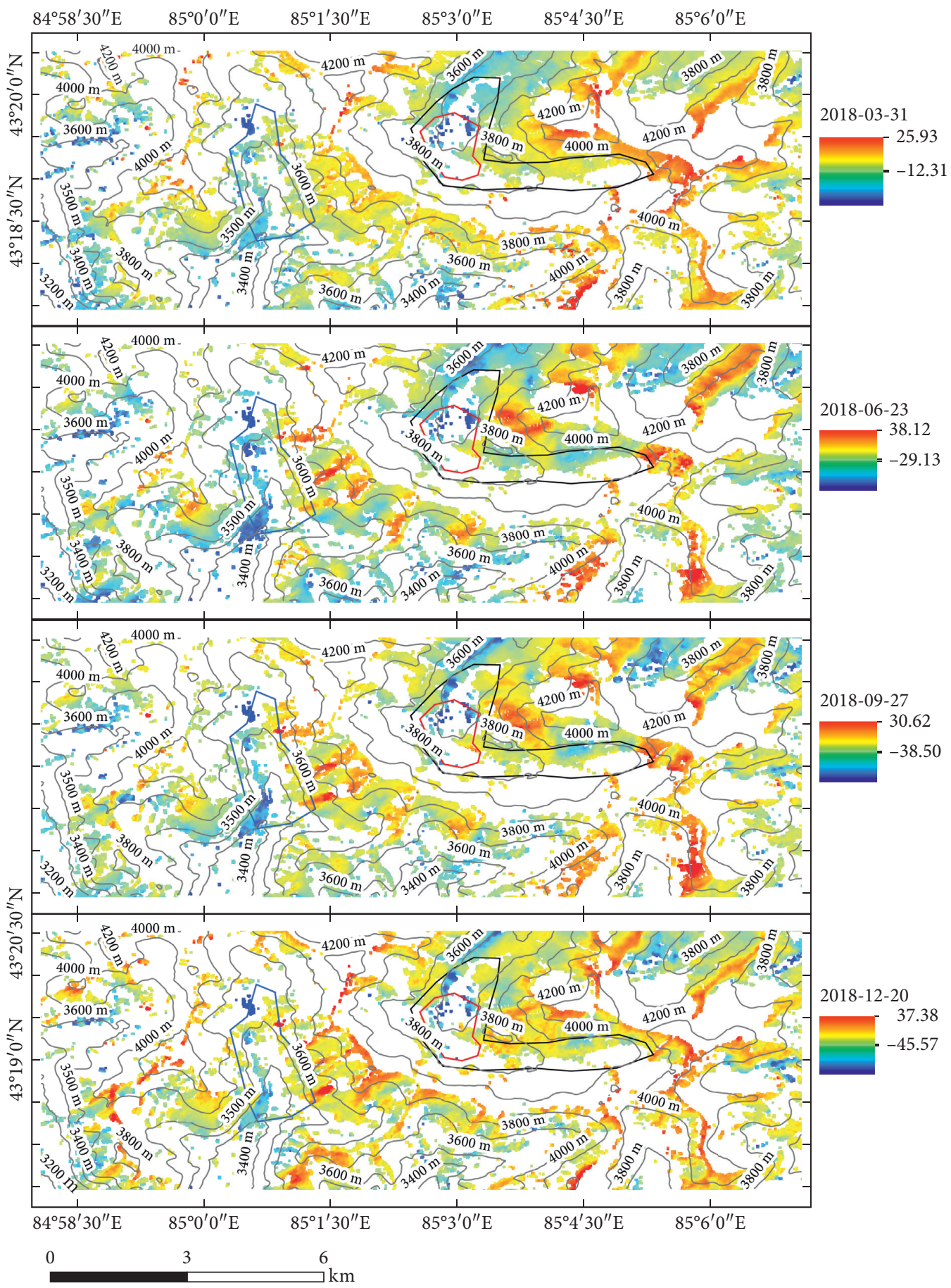

Figure 8: LOS deformation of 2018, in mm.

From Figures 7 and 11, it can be seen that there is good correspondence between the deformation piling volume and the deformation rate value. The settlement volumes at $\mathrm{P} 1$, P3, and P4 increased the most with time, corresponding to the largest deformation rates. The settlement volumes of points P6, P8, and P11 were the second largest, and the settlement rates accelerated after September 2019. The largest amount of accumulation occurred at P5, with an accumulation of more than $70 \mathrm{~mm}$ over the three years, which should be of key concern due to its proximity to the tunnel entrance. P9, P10, and P12 showed the same trend of change with uplift, but the rates of uplift were not large and fluctuated with a certain periodicity, which may be due to the regular manual cleaning and removal of the accumulation. P2 and P7 showed no obvious changes and only slight subsidence. Through the fieldwork and site investigations, it was found that P2 is in the location of the processing plant and P7 is the coal mining ladder of the mining area, both of which are relatively stable, so the deformations therein were not obvious. 


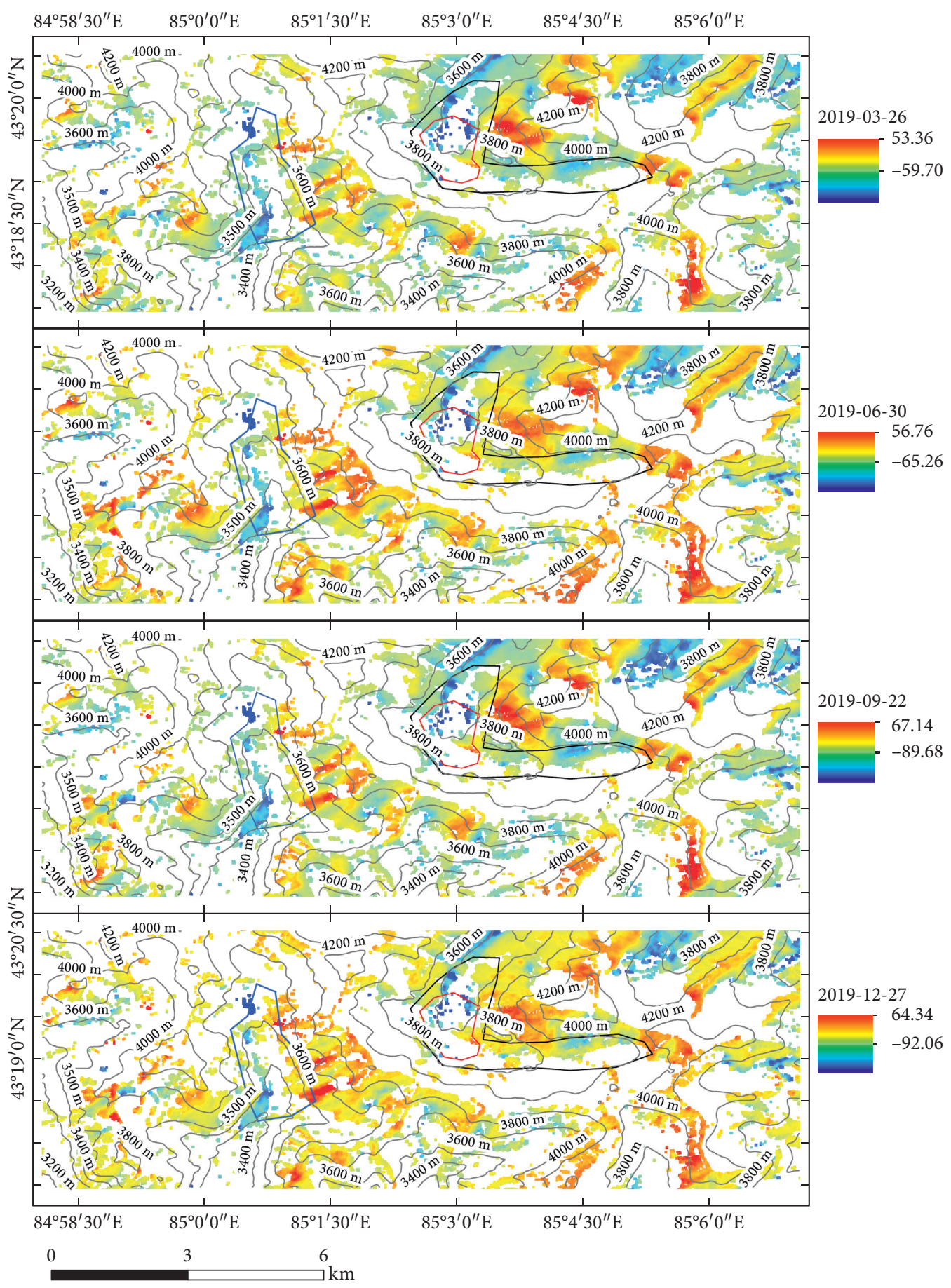

FIGURE 9: LOS deformation of 2019, in $\mathrm{mm}$.

In summary, the tailings accumulation area and the active area mainly showed subsidence in the west along the river distribution section, while they showed uplift in the east near the foot of the mountain. The reason for this phenomenon is mainly due to the presence of a large number of tailings piles distributed along the river area, which are loose structures that are prone to collapse and can accelerate the subsidence phenomenon due to the transport and scouring effects of runoff. The area of accumulation is mainly due to the accumulation of mountain debris slides. To ensure the sustainable development and safe operation of the mine, the mine should minimize the accumulation of tailings in the river flow in the future to reduce water pollution, remove the accumulation of tailings, and carry out vegetation restoration. The piles around the mine should be cleaned regularly to ensure safe mining, and the piles at the tunnel entrance and exit locations should be monitored over a large area for a long period of time and dealt with in a timely manner. 


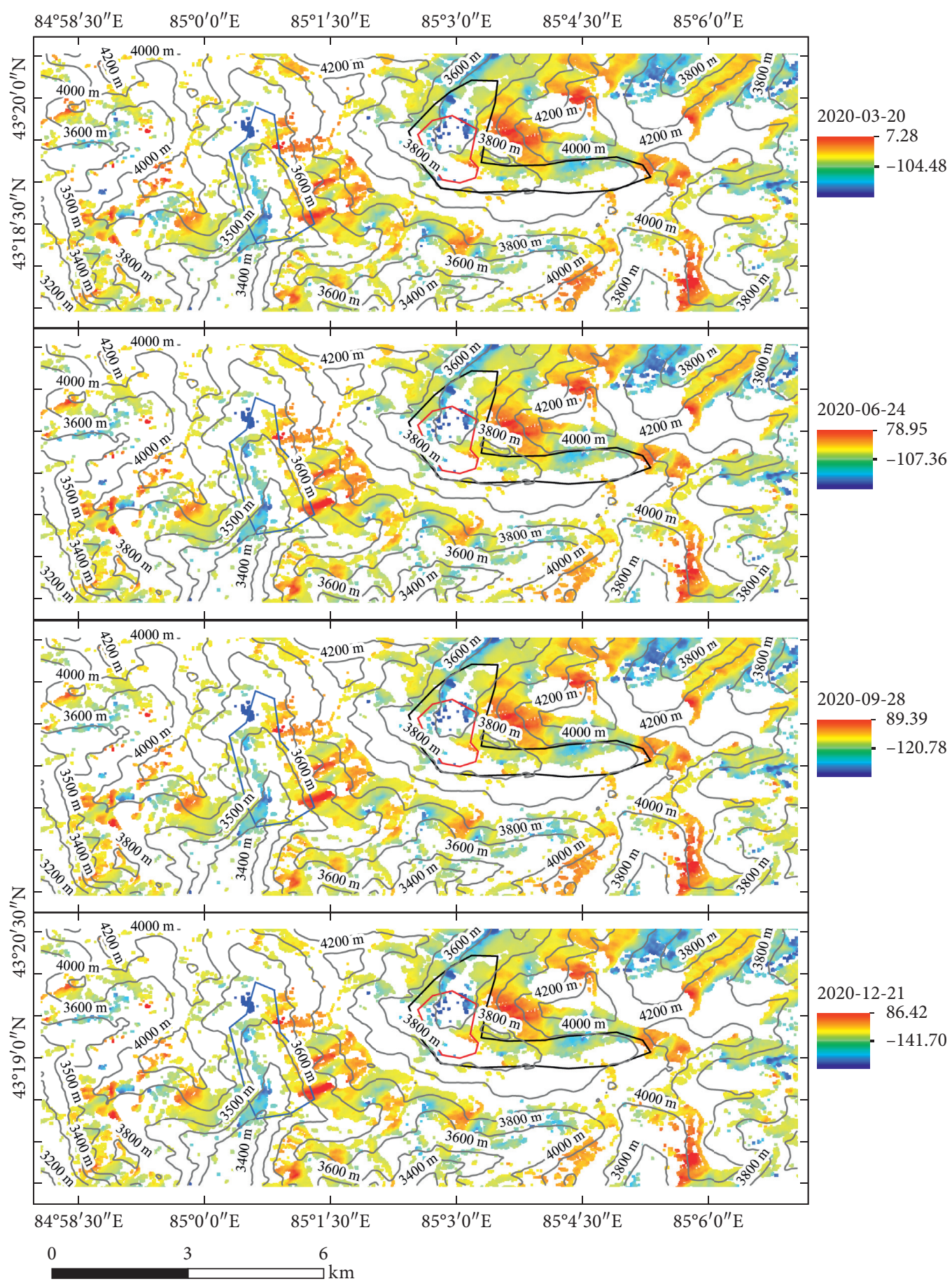

FIGURE 10: LOS deformation of 2020, in $\mathrm{mm}$.

4.4. Deformation Precision. To verify the accuracy of the SBAS-InSAR measurement results, GNSS monitoring data and SBAS-InSAR measurements obtained from $16^{\text {th }}$ October 2019 to $31^{\text {st }}$ May 2020 were selected. The cumulative shape variables for the corresponding dates were calculated using (3), and the results were compared. Theoretically, the location of a GNSS observation point should be exactly the same as the location of a SBAS-InSAR measurement point; however, due to the reason of decoherence, the SBAS-InSAR monitoring results at the precise GNSS installation locations were missing, so points close to each GNSS installation location were selected as the corresponding CPs to obtain the required data for the observation period. The GNSS data were collected at an interval of $2 \mathrm{~h}$, and the temporal resolution of the SBAS-InSAR monitoring results was 12 days. The results are shown in Figure 12.

As can be seen from Figure 12, the accumulations for each set of corresponding points have a high degree of agreement in the general trend, but do not match perfectly, and the GNSS observations are more prominent than the 


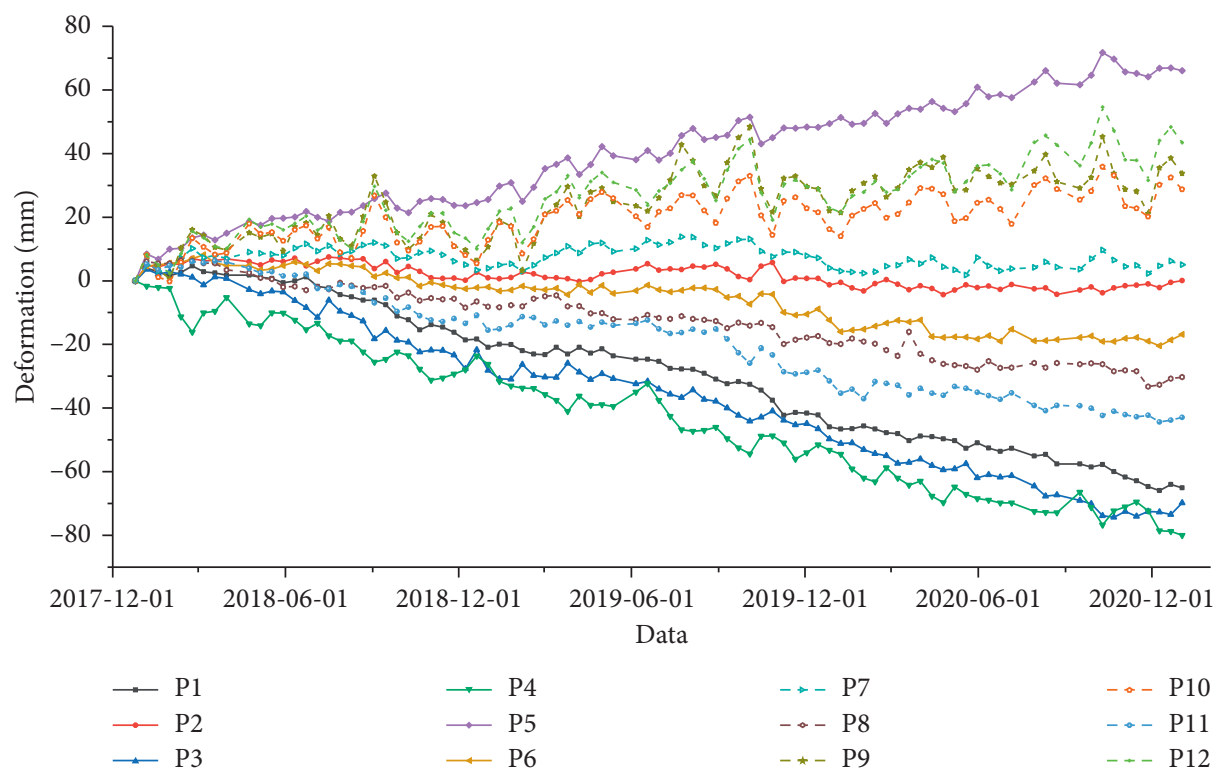

Figure 11: Deformation of the observation points.

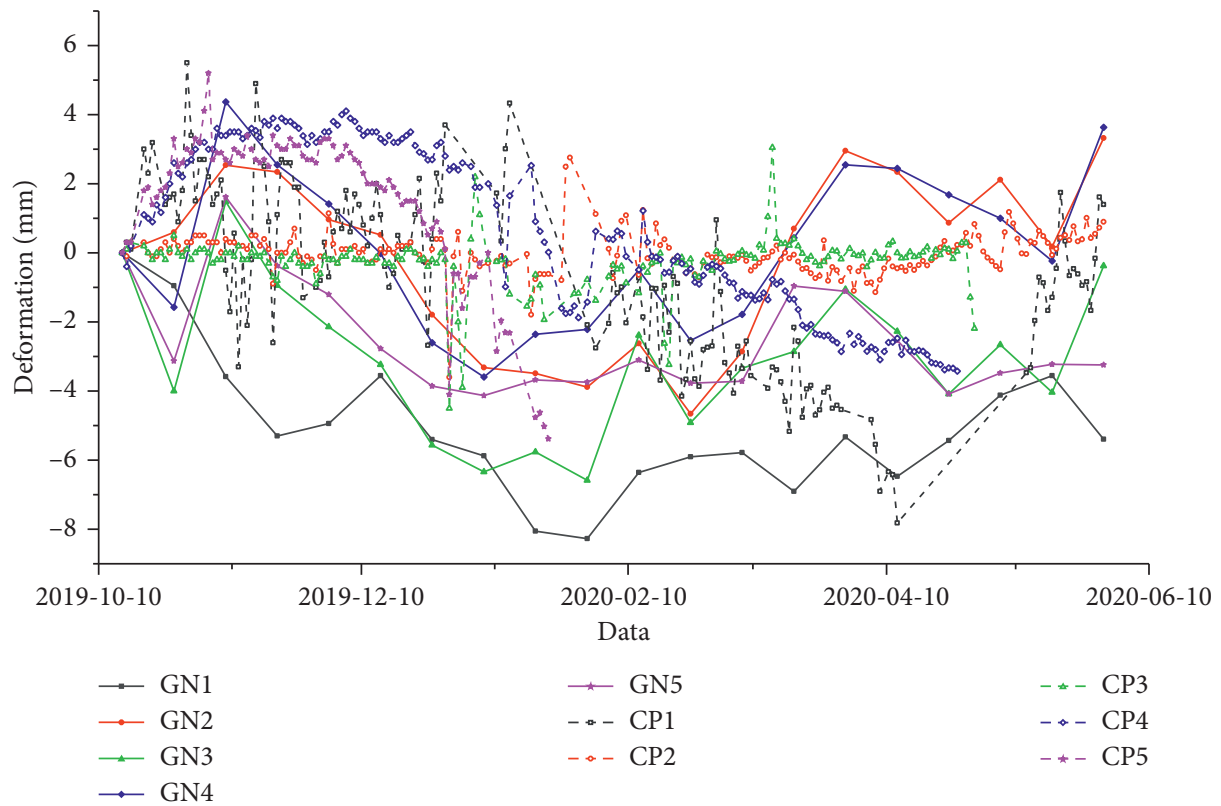

FIGURE 12: Comparison of the SBAS-InSAR results and the GNSS data.

SBAS-InSAR measurements in terms of variability. This phenomenon is mainly due to the inconsistent temporal resolution of the two measurements, the incomplete agreement of the observation locations, and the inconsistent orientation of the deformation values. The deformations measured by SBAS-InSAR are in the LOS direction, while the GNSS deformation measurements were selected along the $x$ direction. Although there are many limitations that lead to some deviations in the two results, the SBAS-InSAR deformation measurements in this area have high accuracy and credibility. These results have an important reference value and can provide a theoretical basis for the restoration of mining environments and the creation of safety measures in mining areas.

In summary, the surface deformation measurement results of alpine mining areas based on SBAS-InSAR technology are highly credible and relatively accurate. Although there is a slight difference from the GNSS field observation results, the measurement results of this method lie in its wide observation range, workload, and less human and material resource requirements. GNSS measurements are highly accurate but costly, due to the large surface undulations in alpine areas and inconvenient transportation, coupled with strong frost splitting, frost stirring, 
congeliturbation, and frost jacking effects. Furthermore, it is difficult to keep the GNSS mounting base fixed, which can easily lead to the collapse of GNSS observation instruments, thus affecting the accuracy of the monitoring results; indeed, frequent repair and maintenance will increase the cost of GNSS observations. Therefore, SBAS-InSAR surface deformation monitoring based on Sentinel-1A has great prospects for applications in alpine and high-altitude mining areas, its monitoring results can provide a theoretical basis for environmental restoration and safety measures for construction activities in mining areas, and its accuracy is sufficient to meet general surveying and mapping requirements.

\section{Discussion}

Surface subsidence measurements based on SBAS-InSAR in alpine and high-altitude areas have proven to provide a wealth of information for mining sites, thus contributing to their sustainable development. However, there are some corresponding problems, such as the deformation information at the location of the mining area not being measured, the presence of a large number of blank areas throughout the study area, and the measured deformation results being in the LOS direction rather than of the vertical rise and fall of mining area deformation.

The above problems are mainly due to the decoherence of the data during differential interference. The location of the study mine is a low-lying gully, and the Sentinel-1A data used in this case are ascending, which has resulted in a significant amount of shadowing, layover, and foreshortening [16] due to the topography. In addition, there are a number of limitations inherent $[14,16]$ to InSAR deformation measurements, including various other phase and noise effects, as well as the correct/incorrect setting of parameters during processing. The influence of the phase manifests itself in the atmospheric phase, the noise of the system itself, and in the terrain phase $[16,21]$. The influence of the parameter settings is mainly in the correct setting of the multiview numbers, the selected filtering methods, and the choice of phase unwrapping methods [66, 67]. The contributions of many scholars in recent years have led to an increasing number of parameters [17] to be set, and how to choose a set of parameters suitable for data processing in the study area requires constant trial and error and summation to obtain the optimal values. The decoherence of the data will result in the measured region being partially masked out and thus appearing as a blank in the deformation result map.

The results of deformation measurements are values in the LOS direction [14], which are limited by the InSAR measurements themselves. To obtain the real $3 \mathrm{D}$ deformation information of the surface, it is necessary to use simultaneous multisource data, multi-incidence angle data, etc., to obtain deformation information along more directions in the study area, so that the true $3 \mathrm{D}$ information of the surface can be solved with the mathematical model $[4,36,37]$.

Therefore, to obtain accurate $3 \mathrm{D}$ surface deformation information, more data must be processed to obtain more deformation information from different aspects, in addition to combining field measurements, retrieving missing measurements by spatial interpolation, etc.

\section{Conclusions}

In alpine and high-altitude regions, due to the development of periglacial landforms such as ice field, ground ice, and rock glaciers, open-pit mining involves extensive surface excavation and massive accumulation of surface tailings, which can cause substantial disturbance to the ecological environment and loosen dangerous rocks around the mining site, thus posing a series of potential threats and risks. In this paper, the deformation information and annual average subsidence rate data of a mining site in Tianshan Mountain from 25 ${ }^{\text {th }}$ December 2017 to $2^{\text {nd }}$ January 2021 were obtained by SBAS-InSAR processing of 89-scene Sentinel-1A ascending SLC data, and the measurement results were compared with field GNSS deformation measurements to verify the former's measurement accuracy. The conclusions of this study are as follows:

(1) Deformation around the mine is significant compared to the rest of the surrounding area. The maximum sedimentation rate in the study area was $44.8 \mathrm{~mm} / \mathrm{a}$, and the maximum uplift was $28.04 \mathrm{~mm} /$ a. The maximum sedimentation rate in the tailings area was $35 \mathrm{~mm} / \mathrm{a}$, and the maximum uplift was $25 \mathrm{~mm} / \mathrm{a}$. The active area, including the mining area, had a maximum sedimentation rate of over $40 \mathrm{~mm} / \mathrm{a}$ and an accumulation rate of $20 \mathrm{~mm} / \mathrm{a}$.

(2) The overall deformation in the study area is dominated by subsidence, with the maximum subsidence amount reaching $129.39 \mathrm{~mm}$ during the three years. The uplift phenomenon is weaker than the subsidence phenomenon, with a maximum uplift accumulation of $60.49 \mathrm{~mm}$ during the three years, which is about half of the maximum subsidence. The tailings accumulation area and the active area are stacked significantly at the foot of the hill near the mountain area, which showed a three-year uplift of over $75 \mathrm{~mm}$, and the tailings accumulation area distributed along the river in the west settled significantly, with a threeyear settlement of over $80 \mathrm{~mm}$.

(3) The deformation measurement results based on SBAS-InSAR are highly accurate and can provide a theoretical basis for environmental restoration and safety measures for construction in mining areas. Compared with GNSS measurements, the method is less costly and less labor intensive. The measurement results cover a large area, including the entire mining site and the surrounding environment, thus providing a macroscopic understanding of the impact of mining activities on the surrounding environment. The data obtained from this method have the potential for widespread use.

\section{Data Availability}

Sentinel-1A level-1 SLC products were downloaded from the ASF website (https://vertex.daac.asf.alaska.edu/); orbital 
data are available from the ESA website (https://qc.sentinel1. eo.esa.int/); DEM can be obtained from the USGS EarthExplorer website (https://earthexplorer.usgs.gov/); and other data are available from the corresponding author upon request.

\section{Conflicts of Interest}

The authors declare that they have no conflicts of interest.

\section{Acknowledgments}

This work was supported by the National Natural Science Foundation of China (No. U1703244), the Second Tibetan Plateau Scientific Expedition and Research Program (No. 2019QZKK0905), and the Foundation of the State Key Laboratory of Frozen Soil Engineering (No. SKLFSE-ZY20). The authors also thank International Science Editing (http://www.internationalscienceediting.com) for editing this paper.

\section{References}

[1] F. G. Bell and L. J. Donnelly, Mining and its Impact on the Environment, CRC Press, Boca Raton, FL, USA, 2014.

[2] Q. S. Du, G. Y. Li, W. L. Pen, M. T. Chai, Y. Zhou, and D. Chen, "Land use changes in high cold-altitude mining area base on remote sensing technology," Environmental Science \& Technology, vol. 43, no. 12, pp. 185-194, 2020.

[3] Z. Lin, B. Zhang, and J. Guo, "Analysis of aWater-inrush disaster caused by coal seam subsidence karst collapse column under the action of multi-field coupling in taoyuan coal mine," Computer Modeling in Engineering \& Sciences, vol. 126, no. 1, pp. 311-330, 2021.

[4] D. P. Sainsbury, B. L. Sainsbury, and E. Sweeney, "Threedimensional analysis of complex anisotropic slope instability at MMG's Century Mine," Mining Technology, vol. 125, no. 4, pp. 212-225, 2016.

[5] A. Schippers, P. G. Jozsa, W. Sand, Z. Maria Kovacs, and M. Jelea, "Microbiological pyrite oxidation in a mine tailings heap and its relevance to the death of vegetation," Geomicrobiology Journal, vol. 17, no. 2, pp. 151-162, 2000.

[6] S. Jiang and Y. M. Wang, "Long-term ground settlements over mined-out region induced by railway construction and operation," Sustainability, vol. 11, no. 3, Article ID 875, 2019.

[7] Q. S. Du and R. J. Zhao, "The production of DEM in SARscape format," Computer Knowledge and Technology, vol. 16, no. 7, pp. 238-239, 2020.

[8] M. T. Chai, G. Y. Li, W. Ma et al., "Assessment of freeze-thaw hazards and water features along the China-Russia crude oil pipeline in permafrost regions," Remote Sensing, vol. 12, no. 21, Article ID 3576, 2020.

[9] Q. S. Du, G. Y. Li, J. M. Li, and Y. Zhou, "Research on the river extraction based on the DEM data in the central west tianshan mountains," China Rural Water and Hydropower, vol. 10, pp. 29-33+40, 2020.

[10] J. F. Wang, Y. L. Liao, and X. Liu, Spatial Data Analysis Tutorial, Science Press, Beijing, China, 2nd edition, 2019.

[11] W. Lodwick, Fuzzy Surfaces in GIS and Geographical Analysis: Theory, Analytical Methods, Algorithms, and Applications, CRC Press, Boca Raton, FL, USA, 2008.
[12] C. Rozenblat and G. Melancon, Methods for Multilevel Analysis and Visualisation of Geographical Networks, Springer, Berlin, Germany, 2013.

[13] A. Ferretti, Satellite InSAR Data: Reservoir Monitoring from Space, EAGE Publications, Houten, Netherlands, 2014.

[14] A. Ferretti, A. Monti-Guarnieri, C. Prati, F. Rocca, and D. Massonnet, InSAR Principles: Guidelines for SAR Interferometry Processing and Interpretation, ESA Publications, Noordwijk, Netherlands, 2007.

[15] N. B. D Bechor and H. A. Zebker, "Measuring twodimensional movements using a single insar pair," Geophysical Research Letters, vol. 33, no. 16, Article ID 26883, 2006.

[16] G. X. Liu, Q. Chen, X. J. Luo, and G. L. Cai, Principle and Application of InSAR, Science Press, Beijing, China, 2019.

[17] R. B. Lohman and M. Simons, "Some thoughts on the use of InSAR data to constrain models of surface deformation: noise structure and data downsampling," Geochemistry, Geophysics, Geosystems, vol. 6, no. 1, Article ID 841, 2005.

[18] N. Zakhvatkina, V. Smirnov, and I. Bychkova, "Satellite sar data-based sea ice classification: an overview," Geosciences, vol. 9, no. 4, Article ID 152, 2019.

[19] B. Han, C. B. Ding, L. H. Zhong et al., "The GF-3 SAR data processor," Sensors, vol. 18, no. 3, Article ID 835, 2018.

[20] J. W. Dong, S. W. Li, K. Yan, and D. J. Fu, Remote Sensing Cloud Computing and Scientific Analysis-Application and Practice, Science Press, Beijing, China, 2020.

[21] J. J. Zhu, Z. W. Li, and J. Hu, "Research progress and methods of InSAR for deformation monitoring," Acta Geodaetica et Cartographic Sinica, vol. 46, no. 10, pp. 1717-1733, 2017.

[22] H. A. Zebker and R. M. Goldstein, "Topographic mapping from interferometric synthetic aperture radar observations," Journal of Geophysical Research, vol. 91, no. B5, pp. 49934999, 1986.

[23] A. K. Gabriel, R. M. Goldstein, and H. A. Zebker, "Mapping small elevation changes over large areas: differential radar interferometry," Journal of Geophysical Research, vol. 94, no. B7, pp. 9183-9191, 1989.

[24] A. Khairi, M. Awaluddin, and B. Sudarsono, "Analisis deformasi seismik sesar matano menggunakan GNSS dan interferometrik SAR," Jurnal Geodesi Undip, vol. 9, no. 2, pp. 32-42, 2020.

[25] A. Ferretti, C. Prati, and F. Rocca, "Nonlinear subsidence rate estimation using permanent scatterers in differential SAR interferometry," IEEE Transactions on Geoscience and Remote Sensing, vol. 38, no. 5, pp. 2202-2212, 2000.

[26] A. Ferretti, C. Prati, and F. Rocca, "Permanent scatterers in SAR interferometry," IEEE Transactions on Geoscience and Remote Sensing, vol. 39, no. 1, pp. 8-20, 2001.

[27] B. Kampes, Radar Interferometry--Persistent Scatterer Technique, Springer, Berlin, Germany, 2014.

[28] P. Berardino, M. Costantini, G. Franceschetti, A. Iodice, L. Pietranera, and V. Rizzo, "Use of differential SAR interferometry in monitoring and modelling large slope instability at Maratea (Basilicata, Italy)," Engineering Geology, vol. 68, no. 1-2, pp. 31-51, 2003.

[29] Y. L. Du, S. Y. Yan, H. N. Yang, J. X. Jiang, and F. Zhao, "Investigation of deformation patterns by DS-InSAR in a coal resource-exhausted region with Spaceborne SAR imagery," Journal of Asian Earth Sciences: X, vol. 5, Article ID 100049, 2021.

[30] A. Pepe and F. Calò, "A review of interferometric synthetic aperture RADAR (InSAR) multi-track approaches for the 
retrieval of Earth's surface displacements," Applied Sciences, vol. 7, no. 12, 2017.

[31] E. Chaussard, F. Amelung, H. Abidin, and S.-H. Hong, "Sinking cities in Indonesia: ALOS PALSAR detects rapid subsidence due to groundwater and gas extraction," Remote Sensing of Environment, vol. 128, pp. 150-161, 2013.

[32] Y. H. Zhang, H. A. Wu, Y. H. Kang, and C. G. Zhu, "Ground subsidence in the beijing-tianjin-hebei region from 1992 to 2014 revealed by multiple SAR stacks," Remote Sensing, vol. 8, no. 8, Article ID 80675, 2016.

[33] B. Xu, G. C. Feng, Z. W. Li, Q. J. Wang, C. C. Wang, and R. G. Xie, "Coastal subsidence monitoring associated with land reclamation using the point target based SBAS-InSAR method: a case study of shenzhen, China," Remote Sensing, vol. 8, no. 8, Article ID 80652, 2016.

[34] C. Carnec, D. Massonnet, and C. King, "Two examples of the use of SAR interferometry on displacement fields of small spatial extent," Geophysical Research Letters, vol. 23, no. 24, pp. 3579-3582, 1996.

[35] H. J. Yin, J. J. Zhu, Z. W. Li, X. L. Ding, and C. C. Wang, "Ground subsidence monitoring in mining area using DInSAR SBAS algorithm," Acta Geodaetica et Cartographica Sinica, vol. 40, no. 1, pp. 52-58, 2011.

[36] N. G. Alex Hay-Man, G. E. Linlin, K. Zhang et al., "Deformation mapping in three dimensions for underground mining using InSAR-Southern highland coalfield in New South Wales, Australia," International Journal of Remote Sensing, vol. 32, no. 22, pp. 7227-7256, 2011.

[37] W. L. Zhi, Z. F. Yang, J. Z. Jian et al., "Retrieving threedimensional displacement fields of mining areas from a single InSAR pair," Journal of Geodesy, vol. 89, no. 1, pp. 17-32, 2015.

[38] H. D. Fan, D. Cheng, K. Z. Deng, B. Q. Chen, and C. G. Zhu, "Subsidence monitoring using D-InSAR and probability integral prediction modelling in deep mining areas," Survey Review, vol. 47, no. 345, pp. 438-445, 2015.

[39] L. Ge, H. C. Chang, and C. Rizos, "Mine subsidence monitoring using multi-source satellite SAR images," Photogrammetric Engineering \& Remote Sensing, vol. 73, no. 3, pp. 259-226, 2005.

[40] Z. Y. Wang, J. Z. Zhang, Y. R. Yu et al., "Monitoring, analyzing, and modeling for single subsidence basin in coal mining areas based on SAR interferometry with L-band data," Scientific Programming, vol. 2021, Article ID 6662097, 10 pages, 2021.

[41] C. Jiang, L. Wang, X. Yu, T. Wei, S. Chi, and Q. Guo, "Prediction of 3D deformation due to large gradient mining subsidence based on InSAR and constraints of IDPIM model," International Journal of Remote Sensing, vol. 42, no. 1, pp. 208-239, 2021.

[42] D. Massonnet, K. Feigl, M. Rossi, and F. Adragna, "Radar interferometric mapping of deformation in the year after the Landers earthquake," Nature, vol. 369, no. 6477, pp. 227-230, 1994.

[43] G. Feng, S. Jónsson, and Y. Klinger, "Which fault segments ruptured in the 2008 wenchuan earthquake and which did not? New evidence from near-fault 3D surface displacements derived from SAR image offsets," Bulletin of the Seismological Society of America, vol. 107, no. 3, pp. 1185-1200, 2017.

[44] X. Tong, B. Smith-Konter, and D. T. Sandwell, "Is there a discrepancy between geological and geodetic slip rates along the San Andreas Fault System?," Journal of Geophysical Research: Solid Earth, vol. 119, no. 3, pp. 25182538, 2014.
[45] J. R. Elliott, R. J. Walters, and T. J. Wright, "The role of spacebased observation in understanding and responding to active tectonics and earthquakes," Nature Communications, vol. 7, Article ID 13844, 2016.

[46] D. Massonnet, P. Briole, and A. Arnaud, "Deflation of Mount Etna monitored by spaceborne radar interferometry," Nature, vol. 375, no. 6532, pp. 567-570, 1995.

[47] J. Ruch, T. Wang, W. B. Xu, M. Hensch, and S. Jónsson, "Oblique rift opening revealed by reoccurring magma injection in central Iceland," Nature Communications, vol. 7, Article ID 12352, 2016.

[48] M. E. Pritchard and M. Simons, "An InSAR-based survey of volcanic deformation in the central Andes," Geochemistry, Geophysics, Geosystems, vol. 5, no. 2, Article ID Q02002, 2004.

[49] J. Eppler and B. Rabus, "Monitoring urban infrastructure with an adaptive multilooking InSAR technique," in Proceedings of Fringes 2011, Frascati, Italy, September 2012.

[50] M. Bakon, D. Perissin, M. Lazecky, and J. Papco, "Infrastructure non-linear deformation monitoring via satellite radar interferometry," Procedia Technology, vol. 16, pp. 294300, 2014

[51] H. Lan, L. Li, H. Liu, and Z. Yang, "Complex urban infrastructure deformation monitoring using high resolution PSI," IEEE Journal of Selected Topics in Applied Earth Observations and Remote Sensing, vol. 5, no. 2, pp. 643-651, 2012.

[52] T. J. Fournier, M. E. Pritchard, and S. N. Riddick, "Duration, magnitude, and frequency of subaerial volcano deformation events: new results from Latin America using InSAR and a global synthesis," Geochemistry, Geophysics, Geosystems, vol. 11, no. 1, Article ID Q01003, 2010.

[53] R. E. Bell, M. Studinger, C. A. Shuman, M. A. Fahnestock, and I. Joughin, "Large subglacial lakes in east Antarctica at the onset of fast-flowing ice streams," Nature, vol. 445, no. 7130, pp. 904-907, 2007.

[54] T. Strozzi, A. Kouraev, A. Wiesmann, U. Wegmüller, A. Sharov, and C. Werner, "Estimation of Arctic glacier motion with satellite L-band SAR data," Remote Sensing of Environment, vol. 112, no. 3, pp. 636-645, 2008.

[55] J. M. Zhou, Z. Li, and Q. Xin, "Deriving glacier border information based on analysis of decorrelation in SAR interferometry," Journal of Glaciology and Geocryology, vol. 32, no. 1, pp. 133-138, 2010.

[56] Y. E. Molan, J. W. Kim, Z. Lu, B. Wylie, and Z. L. Zhu, "Modeling wildfire-induced permafrost deformation in an alaskan boreal forest using InSAR observations," Remote Sensing, vol. 10, no. 3, Article ID 405, 2018.

[57] Z. J. Zhang, M. M. Wang, Z. J. Wu, and X. G. Liu, "Permafrost deformation monitoring along the qinghai-tibet plateau engineering corridor using InSAR observations with multisensor SAR datasets from 1997-2018," Sensors, vol. 19, no. 23, Article ID 5306, 2019.

[58] T. Strozzi, S. Antonnova, F. Günther et al., "Sentinel-1 SAR interferometry for surface deformation monitoring in lowland permafrost areas," Remote Sensing, vol. 10, no. 9, 2018.

[59] C. Xie, Z. Li, J. Xu, and X. Li, "Analysis of deformation over permafrost regions of Qinghai-Tibet plateau based on permanent scatterers," International Journal of Remote Sensing, vol. 31, no. 8, pp. 1995-2008, 2010.

[60] S. Wang, B. Xu, W. Shan, J. C. Shi, Z. W. Li, and G. C. Feng, "Monitoring the degradation of island permafrost using timeseries InSAR technique: a case study of heihe, China," Sensors, vol. 19, no. 6, Article ID 1364, 2019. 
[61] B. Riedel and A. Walther, "InSAR processing for the recognition of landslides," Advances in Geosciences, vol. 14, no. 15, pp. 189-194, 2008.

[62] T. carlà, E. Intrieri, F. Raspini et al., "Perspectives on the prediction of catastrophic slope failures from satellite InSAR," Scientic Reports, vol. 9, Article ID 14137, 2019.

[63] E. Kiseleva, V. Mikhailov, E. Smolyaninova et al., "PS-InSAR monitoring of landslide activity in the black sea coast of the caucasus," Procedia Technology, vol. 16, pp. 404-413, 2014.

[64] J. M. Li, G. Y. Li, W. L. Pen, D. Chen, Y. Zhou, and C. F. Liu, "The strength and deformation characteristics of saturated weathered granite under different temperature conditions," Journal of Glaciology and Geocryology, vol. 42, no. 2, pp. 523-531, 2020.

[65] I. Baran, M. P. Stewart, B. M. Kampes, Z. Perski, and P. Lilly, "A modification to the Goldstein radar interferogram filter," IEEE Transactions on Geoscience and Remote Sensing, vol. 41, no. 9, pp. 2114-2118, 2003.

[66] M. Costantini, "A novel phase unwrapping method based on network programming," IEEE Transactions on Geoscience and Remote Sensing, vol. 36, no. 3, pp. 813-821, 1998.

[67] B. Zhang, J. Li, and H. Ren, "Using phase unwrapping methods to apply D-InSAR in mining areas," Canadian Journal of Remote Sensing, vol. 45, no. 2, pp. 225-233, 2019. 